Pacific Journal of Mathematics

RAMIFICATION AND UNINTEGRATED VALUE DISTRIBUTION 


\title{
RAMIFICATION AND UNINTEGRATED VALUE DISTRIBUTION
}

\author{
J. R. QUINE
}

For a holomorphic map $f$ from the complex plane into the Riemann sphere, the ramification term $n_{1}(f, r)$ is studied. A geometric version of ramification is defined in terms of the intersection points of $f(z) \times$ $f(z+h)$ with the diagonal $\Delta$ for a suitable vector field $h$. Estimates of a counting function for this intersection number are given in terms of the mean covering number.

1. Introduction. Let $S$ be the Riemann sphere normalized with radius $1 / 2 \sqrt{\pi}$ and area 1 . Suppose that $f: \mathbf{C} \rightarrow S$ is a non-constant holomorphic mapping (meromorphic function). Let $B(r)$ denote the ball $|z| \leq r$ in the complex plane. Let $n_{1}(r)$ and $N_{1}(r)$ be the unintegrated and integrated counting functions for ramification as in the value distribution theories of Ahlfors and Nevanlinna ([1], [6]). Let $L(r)=L(f, r)$ denote the length of $f(\partial B(r))$ and $A(r)=A(f, r)$ the area of $f(B(r))$ counting multiplicity (also called the mean covering number).

If $f$ is rational, the total ramification is $2 A-2$ where $A$ is the area or degree. In general, as a consequence of Nevanlinna's second main theorem, we know that there is a set $E$ of finite logarithmic measure such that

$$
N_{1}(r) \leq 2 T(r)+o(T(r))
$$

as $r \rightarrow \infty$ in $\tilde{E}$, where $T$ is the Nevanlinna characteristic. (A derivation of this estimate directly from the Gauss-Bonnet theorem is given in Griffiths [3].) In the unintegrated theory of Ahlfors [1], the term $n_{1}(r)$ disappears from the second main theorem (Nevanlinna [6], p. 350). Although the ramification at the points $a_{1}, \ldots, a_{q}$ is still counted, an inequality analogous to (1) cannot be proven. Terms of the form $o(A(r))$ in Ahlfors theory are given in the form $c L(r)$ where $c$ is a constant. In the class of functions dealt with in this theory, ramification can be added topologically to any given $\left.f\right|_{B(r)}$ while $L(r)$ changes very little. One can imagine adding "loops" of arbitrarily small length to $f(\partial B(r))$. This does suggest, however, that ramification "near" $\partial B(r))$ should not be counted. In the theory of Rickman and the treatment of the Ahlfors theory by Pesonen [7], none of the ramification term is included. (This seems to be an advantage in dealing with higher dimensions.) 
The purpose of this paper is to investigate a modified ramification term in the unintegrated theory and obtain some estimates of the type (1). To do so we abandon the classical notion of ramification and go to a more geometric version. Consider a map of the form $(f(z), f(z+h))$ from $\mathbf{C}$ into $S \times S$ where $h=h(z)$ is some suitably chosen vector (difference) field on $\mathbf{C}$. We will consider $h$ only of the form $c$ or $c z$, where $c$ is a complex constant. Let $f_{h}(z)=f(z+h)$. A point $z_{0}$ where $\left(f \times f_{h}\right)\left(z_{0}\right)$ is in the diagonal $\Delta$ of $S \times S$ is a geometric version of a ramification point. As $h \rightarrow 0$, in fact, these points approach the ramification points of $f$. The advantage of the geometric version is that we can think of the chordal distance from $f$ to $f_{h},\left[f, f_{h}\right]$, as being a measure of "proximity" to $\Delta$. To use the chordal distance, choose $h$ as above and choose $\alpha>0$. Consider the subset of $\mathbf{C}$ determined by the inequality $[f(z), f(z+h)]<\alpha$. This will be a region of $\mathbf{C}$ bounded by the piecewise smooth curve $[f(z)$, $f(z+h)]=\alpha$. Let $P(r, h, \alpha)$ be the union of the components of this set which intersect $\partial B(r)$. These are analogous to the peninsulas in the Ahlfors theory of the counting function for regions in the plane. Let $n_{1}(r, h, \alpha)$ count the number of intersections of $f \times f_{h}$ with $\Delta$ for $z$ in $B(r) \cap \tilde{P}(r, h, \alpha)$. This counts the intersection "far" from $\partial B(r)$. Our main estimate is:

THEOREM 1. Suppose $f \times f_{h}$ does not intersect $\Delta$ on $\partial B(r)$, then

$$
n_{1}(r, h, \alpha) \leq A\left(f_{h}, r\right)+A(f, r)+\frac{1}{\pi \alpha}\left(L\left(f_{h}, r\right)+L(f, r)\right) \text {. }
$$

As an easy corollary, we get

COROLlaRy 1. Let $h(z)=\left(e^{i \beta}-1\right) z$ for $\beta$ real such that the hypothesis of Theorem 1 is satisfied, then for fixed $\alpha>0$ there is a set $E$ of finite logarithmic measure such that

as $r \rightarrow \infty$ in $\tilde{E}$.

$$
n_{1}(r, h, \alpha) \leq 2 A(r)+o(A(r))
$$

The proof is based on an estimate of the form $|\sigma| \leq 2 d s^{\prime}$ where $\sigma$ is a 1-form on $S \times S-\Delta$ such that $d \sigma$ represents the Poincaré dual of $\Delta$, and $d s^{\prime}$ is the naturally defined metric on $S \times S$ (Lemma 1$)$.

2. Definitions. Let $w$ be the usual coordinate system for the finite part of $S$, with $1 / w$ used as a local coordinate near $\infty$. The metric on $S$ is given by

$$
d s=\frac{|d w|}{\sqrt{\pi}\left(1+|w|^{2}\right)}
$$


and the associated area form is

$$
\omega=\frac{i}{2 \omega} \frac{d w \wedge d \bar{w}}{\left(1+|w|^{2}\right)^{2}} .
$$

We consider $S \times S$ as a complex 2 manifold with the product, $\left(w_{1}, w_{2}\right)$, of the usual coordinate system on $S$, plus $\left(1 / w_{1}, w_{2}\right),\left(w_{1}, 1 / w_{2}\right)$, $\left(1 / w_{1}, 1 / w_{2}\right)$ as coordinate patches covering $S \times S$. All computations will be done in the first one. Let $d=\bar{\partial}+\partial$ and $d^{\perp}=i(\bar{\partial}-\partial)$ be the usual differential operators. Recall that $d^{\perp}$ commutes with a holomorphic map. The main rule for computing with these is that $d^{\perp} \operatorname{re} \phi=d \operatorname{im} \phi$ for $\phi$ analytic. The chordal distance is defined on $S$ by

$$
\left[w_{1}, w_{2}\right]=\frac{1}{\sqrt{\pi}} \frac{\left|w_{1}-w_{2}\right|}{\sqrt{1+\left|w_{1}\right|^{2}} \sqrt{1+\left|w_{2}\right|^{2}}}
$$

which can be thought of as a function from $S \times S$ into the reals.

We consider the pullback (pseudo) metric $f^{*}(d s)$ on $\mathbf{C}$, which we will call $d s$ for simplicity. This metric gives a coordinate-free way of expressing the ramification. If $f$ has ramification number $k$ at $z_{0}$, then $d s /|d z|=\left|z-z_{0}\right|^{k} \phi(z)$ where $\phi\left(z_{0}\right) \neq 0$, and $\phi$ is smooth at $z_{0}$. Hence

$$
\lim _{\varepsilon \rightarrow 0} \frac{1}{2 \pi} \int_{\left|z-z_{0}\right|=\varepsilon} d^{\perp} \log \frac{d s}{|d z|}=k .
$$

(See Cowen and Griffiths [2].) If $f \times f_{h}\left(z_{0}\right) \in \Delta$ is an isolated intersection point, define

(6) $\lim _{\varepsilon \rightarrow 0} \frac{1}{2 \pi} \int_{\left|z-z_{0}\right|=\varepsilon} d^{\perp} \log \left[f, f_{h}\right]=\begin{aligned} & \text { intersection number of } f \times f_{h} \\ & \text { with } \Delta \text { at } z_{0} .\end{aligned}$

This is in accord with the usual definition from intersection theory (Guillamin and Pollak [5]). If $f\left(z_{0}\right)$ is finite, then this is also the order of the zero of $w_{1}(z)-w_{2}(z)$ at $z_{0}$.

Let $n_{1}(r, h)$ denote the total number of isolated intersection points, counting multiplicity, of $f \times f_{h}$ with $\Delta$ in $B(r)$. Clearly $\lim _{h \rightarrow 0}\left[f, f_{h}\right] /|h|$ $=d s /|d z|$, hence by (5) and (6) $\lim _{h \rightarrow 0} n_{1}(r, h)=n_{1}(r)-$ number of zeros of $h$ in $B(r)$. This last quantity is 0 or 1 by the way $h$ was chosen. In this sense, the ramification points of $f$ are limit points of the intersection points of $f \times f_{h}$ with $\Delta$.

Since $f \times f_{h}$ is holomorphic, the integrand in (6) is

$$
\left(f \times f_{h}\right)^{*} d^{\perp} \log \left[w_{1}, w_{2}\right],
$$


or the pullback of the 1 -form $d^{\perp} \log \left[w_{1}, w_{2}\right]$ defined on $S \times S-\Delta$. We have

$$
\begin{aligned}
d^{\perp} \log \left[w_{1}, w_{2}\right]= & d^{\perp} \log \left|w_{1}-w_{2}\right| \\
& -\frac{1}{2} d^{\perp}\left(\log \left(1+\left|w_{1}\right|^{2}\right)+\log \left(1+\left|w_{2}\right|^{2}\right)\right) \\
= & d^{\perp} \log \left|w_{1}-w_{2}\right|-\frac{\left|w_{1}\right|^{2}}{1+\left|w_{1}\right|^{2}} d^{\perp} \log \left|w_{1}\right| \\
& -\frac{\left|w_{2}\right|^{2}}{1+\left|w_{2}\right|^{2}} d^{\perp} \log \left|w_{2}\right| .
\end{aligned}
$$

Now taking the differential of (7) and using the fact that

$$
d d^{\perp} \log \left|w_{1}-w_{2}\right|=0,
$$

get

$$
\begin{aligned}
d d^{\perp} \log \left[w_{1}, w_{2}\right] & =-\frac{d\left|w_{1}\right|^{2} \wedge d \arg w_{1}}{\left(1+\left|w_{1}\right|^{2}\right)^{2}}-\frac{d\left|w_{2}\right|^{2} \wedge d \arg w_{2}}{\left(1+\left|w_{1}\right|^{2}\right)^{2}} \\
& =-i \frac{d w_{1} \wedge d \bar{w}_{1}}{\left(1+\left|w_{1}\right|^{2}\right)^{2}}-i \frac{d w_{2} \wedge d \bar{w}_{2}}{\left(1+\left|w_{2}\right|^{2}\right)^{2}} \\
& =-2 \pi\left(\omega_{1}+\omega_{2}\right)
\end{aligned}
$$

on $S \times S-\Delta$, where $\omega_{1}$ is the pullback of $\omega$ by projection on the first coordinate and similarly for $\omega_{2}$.

We remark that as $h \rightarrow 0$, (8) becomes $d d^{\perp} \log d s=-2 \omega$ on $S$. This expresses the fact that the Gaussian curvature of $S$ is 2. Equations (7) and (8) together show $\omega_{1}+\omega_{2}$ is Poincaré dual to $\Delta$ in $S \times S$, or that $d d^{\perp} \log \left[w_{1}, w_{2}\right]$ as a distribution equal to $\Delta-\omega_{1}-\omega_{2}$ (see Griffiths and Harris [4] for the relevant cohomology theory).

3. A preliminary estimate. The key to the proof is an estimate of $\left|d^{\perp} \log \left[w_{1}, w_{2}\right]\right|$ on $S \times S$ in terms of the metric

$$
\left(d s^{\prime}\right)^{2}=\frac{\left|d w_{1}\right|^{2}}{\pi\left(1+\left|w_{1}\right|^{2}\right)^{2}}+\frac{\left|d w_{2}\right|^{2}}{\pi\left(1+\left|w_{2}\right|^{2}\right)} .
$$

The basic idea is exemplified by the differential $d^{\perp} \log |z|=\operatorname{im}(d z / z)$ in the plane minus the origin. Clearly no global estimate of the form $\left|d^{\perp} \log \right| z|| \leq C|d z|$ is possible, but since $\left|d^{\perp} \log \right| z|| \leq|d z| /|z|$ we have 
$\left|d^{\perp} \log \right| z|| \leq|d z| / r_{0}$ in $|z| \geq r_{0}$. The following lemma enables us to estimate $d^{\perp} \log \left[w_{1}, w_{2}\right]$ away from $\Delta$ :

LEMMA 1. On $S \times S-\Delta$,

$$
\left[w_{1}, w_{2}\right]\left|d^{\perp} \log \left[w_{1}, w_{2}\right]\right| \leq 2 d s^{\prime} .
$$

Proof. By (7),

$$
\begin{aligned}
& d^{\perp} \log \left[w_{1}, w_{2}\right]=\operatorname{im}\left(\frac{d w_{2}-d w_{2}}{w_{2}-w_{1}}-\frac{\bar{w}_{1} d w_{1}}{1+\left|w_{1}\right|^{2}}-\frac{\bar{w}_{2} d w_{2}}{1+\left|w_{2}\right|^{2}}\right) \\
& =\operatorname{im}\left(\frac{\left(1+\left|w_{2}\right|^{2}\right)\left(1+\bar{w}_{1} w_{2}\right)\left(-d w_{1}\right)+\left(1+\left|w_{1}\right|^{2}\right)\left(1+\bar{w}_{2} w_{1}\right) d w_{2}}{\left(w_{2}-w_{1}\right)\left(1+\left|w_{1}\right|^{2}\right)\left(1+\left|w_{2}\right|^{2}\right)}\right) \\
& =\operatorname{im}\left(\sigma_{1}-\sigma_{2}\right)
\end{aligned}
$$

where

$$
\sigma_{1}=\frac{\left(1+\bar{w}_{1} w_{2}\right)}{w_{1}-w_{2}} \frac{d w_{1}}{\left(1+\left|w_{1}\right|^{2}\right)}
$$

and $\sigma_{2}$ is defined similarly with $w_{1}$ and $w_{2}$ switched.

Now we have

$$
\begin{aligned}
\frac{\left[w_{1}, w_{2}\right]\left|\sigma_{1}\right|}{d s^{\prime}} & \leq \frac{\left|w_{1}-w_{2}\right|}{\sqrt{1+\left|w_{1}\right|^{2}} \sqrt{1+\left|w_{2}\right|^{2}}}\left|\sigma_{1}\right| \frac{1+\left|w_{1}\right|^{2}}{\left|d w_{1}\right|} \\
& =\frac{\left|1+\bar{w}_{1} w_{2}\right|}{\sqrt{1+\left|w_{1}\right|^{2}} \sqrt{1+\left|w_{2}\right|^{2}}} \leq 1
\end{aligned}
$$

where the last inequality follows from the Cauchy-Schwarz inequality. Similarly, we have

$$
\frac{\left[w_{1}, w_{2}\right]\left|\sigma_{2}\right|}{d s^{\prime}} \leq 1
$$

Now by (11), (12), and (13) we get

$$
\left[w_{1}, w_{2}\right]\left|d^{\perp} \log \left[w_{1}, w_{2}\right]\right| \leq\left[w_{1}, w_{2}\right]\left(\left|\sigma_{1}\right|+\left|\sigma_{2}\right|\right) \leq 2 d s^{\prime} .
$$

This completes the proof of the lemma.

4. Proof of Theorem 1. We now proceed with the proof of Theorem 1. Let $D(r, h, \alpha)=B(r) \cap \tilde{P}(r, h, \alpha)$. We have $\partial D=\partial^{\prime} D+\partial^{\prime \prime} D$ where $\partial^{\prime} D=\partial B \cap \tilde{P}$ and $\partial^{\prime \prime} D=B \cap \partial \tilde{P}$. On $\partial^{\prime \prime} D,\left[f, f_{h}\right]=\alpha$, and the region $\left[f, f_{h}\right]<\alpha$ lies to the right. Thus the directional derivative 
in the direction of vectors pointing to the right is non-positive. Hence $d^{\perp} \log \left[f, f_{h}\right] \leq 0$ along $\partial D^{\prime \prime}$ and

$$
\int_{\partial^{\prime \prime} D} d^{\perp} \log \left[f, f_{h}\right] \leq 0 .
$$

By (6), (7), (8) and Stokes' theorem,

$$
\begin{aligned}
n_{1}(r, h, \alpha)= & \int_{D}\left(f \times f_{h}\right)^{*} \omega_{1}+\int_{D}\left(f \times f_{h}\right)^{*} \omega_{2} \\
& +\frac{1}{2 \pi} \int_{\partial D}\left(f \times f_{h}\right)^{*}\left(d^{\perp} \log \left[w_{1}, w_{2}\right]\right) \\
= & \int_{D} f^{*} \omega+\int_{D} f_{h}^{*} \omega+\frac{1}{2 \pi} \int_{\partial D} d^{\perp} \log \left[f, f_{h}\right] \\
\leq & A(f, r)+A\left(f_{h}, r\right)+\frac{1}{2 \pi} \int_{\partial D} d^{\perp} \log \left[f, f_{h}\right] .
\end{aligned}
$$

Using Lemma (1), (14) and $\left[f, f_{h}\right] \geq \alpha$ on $\partial^{\prime} D$, get

$$
\begin{aligned}
\int_{\partial D} d^{\perp} & \log \left[f, f_{h}\right]=\int_{\partial^{\prime} D} d^{\perp} \log \left[f, f_{h}\right]+\int_{\partial^{\prime \prime} D} d^{\perp} \log \left[f, f_{h}\right] \\
& \leq \int_{\partial^{\prime} D} d^{\perp} \log \left[f, f_{h}\right] \leq \frac{2}{\alpha} \int_{\partial^{\prime} D}\left(f \times f_{h}\right)^{*} d s^{\prime} \\
& =\frac{2}{\alpha} \int_{\partial^{\prime} D} \frac{1}{\sqrt{\pi}}\left(\frac{|d f|^{2}}{\left(1+|f|^{2}\right)^{2}}+\frac{\left|d f_{h}\right|^{2}}{\left(1+\left|f_{h}\right|^{2}\right)^{2}}\right)^{1 / 2} \\
& \leq \frac{2}{\alpha} \int_{\partial^{\prime} D} \frac{1}{\sqrt{\pi}} \frac{|d f|}{1+|f|^{2}}+\frac{2}{\alpha} \int_{\partial^{\prime} D} \frac{1}{\sqrt{\pi}} \frac{\left|d f_{h}\right|}{1+\left|f_{h}\right|^{2}} \\
& \leq \frac{2}{\alpha} \int_{\partial B} \frac{1}{\sqrt{\pi}} \frac{|d f|}{1+|f|^{2}}+\frac{2}{\alpha} \int_{\partial B} \frac{1}{\sqrt{\pi}} \frac{\left|d f_{h}\right|}{1+\left|f_{h}\right|^{2}} \\
& =\frac{2}{\alpha}\left(L(f, r)+L\left(f_{h}, r\right)\right) .
\end{aligned}
$$

Now (15) and (16) combined give Theorem 1.

To prove the Corollary, note that $f_{h}(z)=f\left(z e^{i \beta}\right)$ so that in this case $A\left(f_{h}, r\right)=A(f, r)$ and $L\left(f_{h}, r\right)=L(f, r)$. The estimate on $L(r)$ is obtained in the usual manner (Nevanlinna [6], p. 350).

5. Conclusion. The above gives, at least in principle, a way to derive bounds on a term $n_{1}(r, h, \alpha)$ related to ramification and dependent on two parameters $h$ and $\alpha$. In Corollary 1 since the right-hand-side of the 
inequality is independent of $h$, we can choose $h=h_{r}$ such that $\left[f, f_{h}\right] /|h|$ $\rightarrow d s /|d z|$ in $B(r)$ as $r \rightarrow \infty$. If $\alpha=\alpha_{r}$ and $\alpha_{r} /\left|h_{r}\right| \rightarrow 0$ as $r \rightarrow \infty$ then $n_{1}\left(r, h_{r}, \alpha_{r}\right) \rightarrow n_{1}(r)$ as $r \rightarrow \infty$, however $\alpha_{r}$ must remain bounded below to get the uniform estimate on the remainder term.

The purpose of the paper was to establish two facts: first that by looking at maps from $\mathrm{C} \times \mathbf{C}$ to $S \times S$, the corresponding counting function $n_{1}$ can be treated in a way analogous to the counting function for domains in the Ahlfors theory; secondly, that it is possible to obtain bounds of the form $c L$ on the remainder term in the unintegrated theory by proving an inequality of the form $\left|d^{\perp} \log \left[w_{1}, w_{2}\right]\right| \leq d s^{\prime}$ on $S \times S$. The hope is that such an approach will establish a basis for proving the Ahlfors defect relation in a way that can be extended to higher dimensions and for which a treatment of the $n_{1}$ term is possible.

\section{REFERENCES}

[1] L. V. Ahlfors, Zur Theorie der Uberlagerungsflächen, Acta. Math., 65 (1935).

[2] M. Cowen and P. Griffiths, Holomorphic curves and metrics of negative curvature, J. D’Anal. Math., 29 (1976), 93-153.

[3] P. Griffiths, Entire Holomorphic Mappings in One and Several Complex Variables, Princeton, 1976.

[4] P. Griffiths and J. Harris, Principles of Algebraic Geometry, Wiley, 1978.

[5] V. Guillemin and A. Pollack, Differential Topology, Prentice-Hall, 1974.

[6] R. Nevanlinna, Analytic Functions, Springer-Verlag, 1970.

[7] M. Pesonen, A path family approach to Ahlfor's value distribution theory, Ann. Acad. Sci. Fenn. Ser. AI Math. Dissertationes 39, 1982.

Received June 28, 1984.

The Florida State University

TALlAHASSEE, FL 32306

AND

THE INSTITUTE FOR ADVANCED STUDY

PRINCETON, NJ 08540 



\section{PACIFIC JOURNAL OF MATHEMATICS EDITORS}

\author{
V. S. VARAdarajan (Managing Editor) \\ University of California \\ Los Angeles, CA 90024 \\ Hebert Clemens \\ University of Utah \\ Salt Lake City, UT 84112 \\ Charles R. DePrima \\ California Institute of Technology \\ Pasadena, CA 91125
}

R. FINN

Stanford University

Stanford, CA 94305

HeRManN FLASChKa

University of Arizona

Tucson, AZ 85721

RAMESH A. GANGOlli

University of Washington

Seattle, WA 98195

ROBION KIRBY

University of California

Berkeley, CA 94720

\author{
C. C. MOORE \\ University of California \\ Berkeley, CA 94720 \\ H. SAMELSON \\ Stanford University \\ Stanford, CA 94305 \\ HAROLD STARK \\ University of California, San Diego \\ La Jolla, CA 92093
}

\section{ASSOCIATE EDITORS}

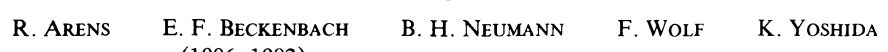

(1906-1982)

\section{SUPPORTING INSTITUTIONS}

\begin{abstract}
UNIVERSITY OF ARIZONA
UNIVERSITY OF BRITISH COLUMBIA

CALIFORNIA INSTITUTE OF TECHNOLOGY

UNIVERSITY OF CALIFORNIA

MONTANA STATE UNIVERSITY

UNIVERSITY OF NEVADA, RENO

NEW MEXICO STATE UNIVERSITY

OREGON STATE UNIVERSITY
\end{abstract}

\author{
UNIVERSITY OF OREGON \\ UNIVERSITY OF SOUTHERN CALIFORNIA \\ STANFORD UNIVERSITY \\ UNIVERSITY OF HAWAII \\ UNIVERSITY OF TOKYO \\ UNIVERSITY OF UTAH \\ WASHINGTON STATE UNIVERSITY \\ UNIVERSITY OF WASHINGTON
}

The Supporting Institutions listed above contribute to the cost of publication of this Journal, but they are not owners or publishers and have no responsibility for its content or policies.

Mathematical papers intended for publication in the Pacific Journal of Mathematics should be in typed form or offset-reproduced (not dittoed), double spaced with large margins. Please do not use built up fractions in the text of the manuscript. However, you may use them in the displayed equations. Underline Greek letters in red, German in green, and script in blue. The first paragraph must be capable of being used separately as a synopsis of the entire paper. In particular it should contain no bibliographic references. Please propose a heading for the odd numbered pages of less than 35 characters. Manuscripts, in triplicate, may be sent to any one of the editors. Please classify according to the scheme of Math. Reviews, Index to Vol. 39. Supply name and address of author to whom proofs should be sent. All other communications should be addressed to the managing editor, or Elaine Barth, University of California, Los Angeles, California 90024.

There are page-charges associated with articles appearing in the Pacific Journal of Mathematics. These charges are expected to be paid by the author's University, Government Agency or Company. If the author or authors do not have access to such Institutional support these charges are waived. Single authors will receive 50 free reprints; joint authors will receive a total of 100 free reprints. Additional copies may be obtained at cost in multiples of 50 .

The Pacific Journal of Mathematics is issued monthly as of January 1966. Regular subscription rate: $\$ 190.00$ a year (5 Vols., 10 issues). Special rate: $\$ 95.00$ a year to individual members of supporting institutions.

Subscriptions, orders for numbers issued in the last three calendar years, and changes of address should be sent to Pacific Journal of Mathematics, P.O. Box 969, Carmel Valley, CA 93924, U.S.A. Old back numbers obtainable from Kraus Periodicals Co., Route 100, Millwood, NY 10546.

The Pacific Journal of Mathematics at P.O. Box 969, Carmel Valley, CA 93924 (ISSN 0030-8730) publishes 5 volumes per year. Application to mail at Second-class postage rates is pending at Carmel Valley, California, and additional mailing offices. Postmaster: Send address changes to Pacific Journal of Mathematics, P.O. Box 969, Carmel Valley, CA 93924.

PUBLISHED BY PACIFIC JOURNAL OF MATHEMATICS, A NON-PROFIT CORPORATION

Copyright $\odot 1986$ by Pacific Journal of Mathematics 


\section{Pacific Journal of Mathematics}

\section{Vol. 122, No. 2 \\ February, 1986}

Gideon Amit and David Chillag, On a question of Feit concerning character values of finite solvable groups ......................257

Constantin Gelu Apostol and Frank Larkin Gilfeather, Isomorphisms modulo the compact operators of nest algebras ................263

Parviz Azimi and James Neil Hagler, Examples of hereditarily $l^{1}$ Banach

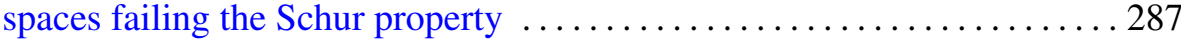

Brian Evan Blank, Boundary behavior of limits of discrete series representations of real rank one semisimple groups . . . . . . . . . . 299

Jeffrey Carroll, Some undecidability results for lattices in recursion theory

Gerald Howard Cliff and Alfred Rheinhold Weiss, Crossed product and

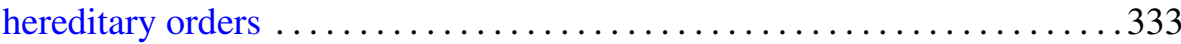

Ralph Cohen, Realizing transfer maps for ramified coverings . . . . . . . . 347

Ronald James Evans, Hermite character sums . .................. 357

C. L. Frenzen and Roderick Sue-Chuen Wong, Asymptotic expansions of the Lebesgue constants for Jacobi series . . . . . . . . . . . . . . . . 391

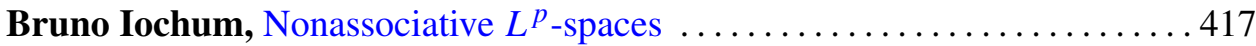

John McDonald, Unimodular approximation in function algebras ....... 435

John Robert Quine, Jr., Ramification and unintegrated value distribution . . 441

Marc Raphael, Commutants of quasisimilar subnormal operators ........ 449

Parameswaran Sankaran and Peter Zvengrowski, On stable

parallelizability of flag manifolds

Helga Schirmer, A relative Nielsen number

Barry Simon, Schrödinger semigroups on the scale of Sobolev spaces . . . . . 475

Viakalathur Shankar Sunder, Stochastic integration in Fock space

Jan de Vries, A note on the $G$-space version of Glicksberg's theorem 